\title{
ASSOCIAÇÃO ENTRE A DENSIDADE DO COLOSTRO E A TRANSFERÊNCIA DE IMUNIDADE PASSIVA EM BEZERROS NEONATOS, NASCIDOS DE FÊMEAS NULÍPARAS.
}

José Ricardo Cecilio Junqueira, Aline de Souza Silva, Vanessa Sartoreli dos Santos, Daniele Cristina Voltarelli, Rogério Giuffrida, Ana Maria Siqueira Silveira.

Medicina Veterinária, Departamento de Clínica Médica de Grandes Animais - Universidade do Oeste Paulista UNOESTE. E-mail: junqueira@unoeste.br

\section{RESUMO}

Este estudo objetiva determinar à eficácia da transferência da imunidade passiva (TIP) em bezerros neonatos nascidos de fêmeas nulíparas, correlacionando a densidade do colostro com os níveis da proteína plasmática total (PPT) e da enzima gama glutamiltransferase (GGT) após a ingestão do colostro. Amostras de sangue dos bezerros foram colhidas em momentos predeterminados 24,48 e 72 horas de vida e 7, 14, 28, 35 e 42 após o parto. Os testes empregados para determinação da PPT, e da GGT foram confrontados com a densidade e qualidade do colostro com o auxilio do colostrômetro. A concentração da PPT (M1 6,960 \pm 1,580) e da enzima GGT (M1 $536,68 \pm 275,37)$ nos neonatos foram compatíveis com a qualidade do colostro recebido. Assim podemos inferir que os testes empregados para avaliação de TIP por meio da concentração de PPT, GGT e qualidade do colostro foram eficientes.

Palavras-chave: Imunoglobulinas, bovinos, recém-nascido, ingestão de colostro.

\section{INTRODUÇÃO}

A placenta é o órgão de nutrição, respiração, filtração e de secreção endócrina do feto, assim como o protege de alguns patôgenos virais e bacterianos (JAINUDEEN; HAFEZ, 2004).

Nos bovinos a placenta é classificada como sinepiteliocorial, esse tipo de placenta impossibilita a passagem de anticorpos da mãe para o feto, por ser impermeável as imunoglobulinas não ocorre a transferência de imunidade durante a gestação. Essa só ocorrerá após o nascimento, através da ingestão de colostro (LANDIM-ALVARENGA, 2006).

O colostro é produzido nas ultimas semanas que antecedem o parto através de influencia hormonal, onde ocorre a transferência de imunoglobulinas (IgG, IgM e $\lg A$ ), proteínas, gorduras, vitaminas e minerais do sangue materno para a glândula mamária (RADOSTITS, 2000).

Existem três tipos de imunoglobulinas (Igs) presentes no colostro bovino, cada uma desempenha determinada função: a IgG representa $70-80 \%$ das Igs presente no colostro sendo sua principal função identificar e destruir patôgenos. Em menor concentração a IgA representa 10$15 \%$ das Igs tendo papel de proteção as mucosas, como por exemplo, ligando-se a parede do intestino e evitando a adesão de possíveis patôgenos a mucosa. Assim como a $\lg$ A a $\lg M$ 
representa $10-15 \%$ das Igs servindo como primeira linha de defesa nos casos de septicemia (BOLZAN et al., 2010).

Após o nascimento os bezerros devem ingerir um volume de colostro correspondente a $10 \%$ do seu peso, sendo metade fornecida dentro das primeiras seis horas pós-parto e o restante até doze horas, não ultrapassando vinte e quatro horas, onde se iniciará o "fechamento" do intestino delgado do neonato e o colostro começará a perder sua qualidade (PARISH, 1996). Os bezerros de raças leiteiras de grande porte devem ingerir no mínimo 4 litros de colostro (MORIN et al., 1997).

Nos bezerros o pico de imunoglobulinas no soro são alcançados de 12-24 horas após o nascimento (TIZARD, 2002), o nível de IgG diminui lentamente e alcança valor mínimo em torno dos 60 dias, já a IgM e a IgA declinam rapidamente e atingem valor mínimo próximo ao $21^{\circ}$ dia de idade (RADOSTITS, 2000).

Existem três razões para que ocorra falha de transferência de imunidade passiva (FTIP). Em primeiro lugar, relacionado à mãe e a produção, a mãe pode produzir pouco colostro, de má qualidade ou ainda receber manejo errado. Em segundo lugar, referente à falha da ingestão, que pode haver produção suficiente de colostro, mas um consumo inadequado por parte do recémnascido, por abandono da mãe, conformação inadequada da glândula e/ou dos tetos, ou ainda por influência das condições do nascimento. Em terceiro lugar, pode existir falha na absorção intestinal, por ingestão tardia do colostro e interferência na absorção (FEITOSA, 1999).

Existem algumas maneiras de determinar a FTIP em bezerros neonatos, as quais serão descritas a seguir e abordadas neste trabalho:

- Proteína Plasmática Total (PPT): As imunoglobulinas colostrais absorvidas representam o principal componente do teor de proteína total do plasma de neonatos, a concentração de PPT em bezerros aumenta até $2 \mathrm{~g} / \mathrm{dl}$ após a ingestão do colostro. Desse modo, a dosagem de PPT em bezerros tem sido considerada um indicador de concentração plasmática de imunoglobulinas e, por tanto, um parâmetro para avaliar a adequada transferência de imunidade passiva. A refratometria é um procedimento simples que requer apenas uma centrifuga simples de microhematocrito para separar o plasma da fração celular e um refratômetro. Os limites são variáveis, mais leituras séricas de 4,2 a 5,5 g/dl são indicativos de boa transferência de imunidade passiva (REA et al., 1996.; TYLER et al., 1998.; DONOVAN et al., 1998), já que concentração sérica de PPT de $5,2 \mathrm{~g} / \mathrm{dl}$ corresponde ao equivalente de $1.000 \mathrm{mg} / \mathrm{dl}$ de IgG (TYLER et al., 1996). O ensaio colorimétrico pela técnica do biureto é um método direto de elevada sensibilidade que apresenta resultado de medição linear entre 1,0 e 14,0 g/dl (Kaneko et al., 1997). 
Encontro de Ensino, Pesquisa e Extensão, Presidente Prudente, 21 a 24 de outubro, 2013

- Atividade sérica da Gama Glutamil Transferase (GGT): Este teste é usado para determinar a eficácia da transferência da imunidade passiva em bezerros e cordeiros. As concentrações de GGT são altas no colostro de ruminantes, e a atividade sérica da GGT em bezerros e cordeiros que mamaram ou foram alimentados com colostro pode atingir 200 vezes o limite superior de normalidade de animais adultos, durante os 3 dias de vida (PERINO et al., 1993.; TESSMAN et al., 1997). A meia vida da GGT no colostro é curta, e a GGT sérica cai significativamente na primeira semana de vida. Os valores séricos da GGT equivalentes a uma concentração sérica IgG de $10 \mathrm{mg} / \mathrm{ml}$ são de $200 \mathrm{Ul} / \mathrm{l}$ no primeiro dia de vida e de $100 \mathrm{Ul}$ no quarto dia de vida. As concentrações séricas de GGT menores de que 50UI/I indicam falha na transferência da imunidade passiva (PERINO et al., 1993.; PARISH et al., 1997).

Sabendo-se que a FTP pode também estar relacionada com a qualidade do colostro, podese fazer duas avaliações:

- Avaliação da densidade e qualidade do colostro, com Colostrômetro: Esta avaliação é realizada com o auxílio do colostrômetro, que mede a densidade do colostro e a relaciona com a concentração de imunoglobulinas G (IgG). A qualidade é avaliada em três categorias: vermelha que é ruim com até $20 \mathrm{mg} / \mathrm{ml}$ de lgG; amarelo, intermediário, que varia de 21 a $50 \mathrm{mg} / \mathrm{ml}$ e verde, que é colostro de alta qualidade, com mais de $51 \mathrm{mg} / \mathrm{ml}$ de IgG (COELHO; SILPER, 2008).

Este estudo teve como objetivo determinar à eficácia da transferência da imunidade passiva (TIP) em bezerros neonatos nascidos de fêmeas nulíparas, correlacionando a densidade do colostro e os níveis plasmáticos da proteína total e da enzima gama glutamiltransferase após a ingestão do colostro.

\section{METODOLOGIA}

Foram empregadas 10 novilhas (N1 a N10) com aptidão leiteira, com média de produção de dez litros, criadas a pasto, com escore corporal entre 3 e 4 (escala de 0 à 5), e 10 bezerros (B1 a B10) neonatos nascidos dessas novilhas, sem distinção de sexo, os quais permaneceram com as mães por um período de até 72 horas ingerindo colostro "ad libitum", oriundos do Centro Zootécnico da Universidade do Oeste Paulista (UNOESTE).

Amostras de sangue venoso por punção da jugular foram colhidas dos 10 bezerros em momentos (M) predeterminados que serão relatados a seguir: M1: 24 horas de vida; M2: 48 horas de vida; M3: 72 horas de vida; M4: 7 dias de vida; M5: 14 dias de vida; M6: 28 dias de vida; M7: 35 dias de vida; M8: 42 dias de vida. 
Encontro de Ensino, Pesquisa e Extensão, Presidente Prudente, 21 a 24 de outubro, 2013

As determinações plasmáticas de proteína total (PPT) foram feitas por refratômetria e a determinação sérica da enzima Gama Glutamiltransferase (GGT) pelo método cinético em tempo fixo.

A avaliação da densidade e qualidade do colostro foi realizada no primeiro momento pósparto por intermédio do colostrômetro.

Inicialmente empregou-se o teste de Kolmogov-Smirnov para avaliar a normalidade dos dados, pelo qual todas as variáveis analisadas foram consideradas como paramétricas $(p>0,10)$. Para determinar se os valores dos parâmetros mensurados diferiram significativamente ao longo dos momentos pesquisados foi utilizada a análise de variância para dados pareados, com contrastes pelo método de Tukey. Todas as análises foram realizadas utilizando o pacote computacional Bioestat (AYRES et al. 2007), com nível de significância de 5\%. Protocolo de aprovação no CEUA $\mathrm{n} \times 538$.

\section{RESULTADOS}

Os resultados obtidos para PPT demonstraram que M1 foi significativamente maior que os valores de M6 $(p<0,01), M 7$ e M8 $(p<0,05)$. Os valores de M2 e M3 foram significativamente maiores que o valor de M6 $(p<0,05)$ como se pode observar na tab. 1. Já para a GGT, M1 apresentou valores significativamente maiores $(p<0,001)$ que M6, M7 e M8; M2 foi significativamente maior $(p<0,001)$ que M6, M7, e M8, e M3 foi significativamente maior $(p<0,001)$ que $M 6, M 7$ e M8 demonstrando níveis elevados da atividade sérica de GGT até o M3 (72 horas de vida) (tab. 1).

Tabela 1. Médias e desvios-padrão das concentrações plasmática de proteína total (PPT) e gama glutamil transferase (GGT) em dez bezerros leiteiros mestiços, nascidos de fêmeas nulíparas, Presidente Prudente, 2013.

\begin{tabular}{|c|c|c|c|c|c|c|c|c|}
\hline \multirow{2}{*}{ Parâmetro } & \multicolumn{8}{|c|}{ Dias pós-mamada do colostro } \\
\hline & 1 & 2 & 3 & 7 & 14 & 28 & 35 & 42 \\
\hline PT & $\begin{array}{c}6,960 \pm \\
1,580 *\end{array}$ & $\begin{array}{c}6,800 \pm \\
1,320^{\S}\end{array}$ & $\begin{array}{c}6,860 \pm \\
1,163^{\text {回 }}\end{array}$ & $\begin{array}{l}6,740 \pm \\
0,9192\end{array}$ & $\begin{array}{l}6,480 \pm \\
0,7254\end{array}$ & $\begin{array}{l}6,020 \pm \\
0,5922\end{array}$ & $\begin{array}{l}6,100 \pm \\
0,3559\end{array}$ & $\begin{array}{c}6,160 \\
\pm \\
0,4088\end{array}$ \\
\hline GGT & $\begin{array}{c}536,68 \\
\pm \\
275,37^{\infty}\end{array}$ & $\begin{array}{c}527,40 \pm \\
343,54 \#\end{array}$ & $\begin{array}{l}558,96 \pm \\
381,82^{\Phi}\end{array}$ & $\begin{array}{c}382,27 \pm \\
259,27^{\ddagger}\end{array}$ & $\begin{array}{c}264,37 \pm \\
348,12\end{array}$ & $\begin{array}{c}69,230 \\
\pm \\
65,107 \\
\end{array}$ & $\begin{array}{c}43,00 \pm \\
37,153\end{array}$ & $\begin{array}{c}25,40 \\
\pm \\
20,244 \\
\end{array}$ \\
\hline
\end{tabular}

*valor significativamente maior em relação aos dias $28(p<0,01), 35$ e $42(p<0,05)$; $^{8}$ valor significativamente maior em relação ao dia $28(p<0,05)$; valor significativamente maior em relação ao dia $28(p<0,05) ;{ }^{\infty}$ valor significativamente maior em relação aos dias 28,35 e $42(p<0,001)$; \# valor significativamente maior em relação aos dias 28,35 e 42 $(p<0,001) ;{ }^{\Phi}$ valor significativamente maior em relação aos dias 28,35 e $42(p<0,001){ }^{\ddagger}$ valor significativamente maior em relação aos dias, 35e $42(p<0,05)$; 
Encontro de Ensino, Pesquisa e Extensão, Presidente Prudente, 21 a 24 de outubro, 2013

Tabela 2. Valores de Proteína Plasmática Total (PPT) dos dez animais nos 8 momentos (M) em g / dl.

\begin{tabular}{c|cccccccc}
\hline Animais & M1 & M2 & M3 & M4 & M5 & M6 & M7 & M8 \\
\hline B1 & 5,4 & 5,4 & 5,6 & 5,6 & 6,0 & 5,4 & 5,8 & 5,8 \\
B2 & 4,8 & 4,8 & 5,4 & 5,4 & 6,0 & 5,4 & 6 & 5,6 \\
B3 & 4,4 & 4,8 & 5,0 & 5,4 & 5,4 & 5,0 & 5,6 & 5,6 \\
B4 & 7,4 & 7,4 & 7,0 & 7,4 & 6,6 & 6,2 & 6,0 & 6,0 \\
B5 & 6,6 & 7,0 & 6,6 & 6,8 & 6,0 & 6,0 & 6,6 & 6,2 \\
B6 & 8,0 & 7,6 & 7,6 & 7,4 & 7,0 & 7,0 & 6,4 & 6,4 \\
B7 & 8,2 & 7,6 & 7,6 & 7,4 & 6,8 & 6,4 & 5,6 & 6,6 \\
B8 & 8,8 & 8,4 & 8,4 & 7,8 & 8,0 & 6,2 & 6,2 & 6,8 \\
B9 & 8,4 & 8,0 & 7,8 & 7,2 & 6,8 & 6,2 & 6,4 & 6,4 \\
B10 & 7,6 & 7,0 & 7,6 & 7,0 & 6,2 & 6,4 & 6,4 & 6,2 \\
\hline
\end{tabular}

Tabela 3. Concentração sérica da enzima Gama Glutamil Transferase (GGT) dos dez animais nos 8 momentos (M) em UI/L.

\begin{tabular}{c|cccccccc}
\hline Animais & M1 & M2 & M3 & M4 & M5 & M6 & M7 & M8 \\
\hline B1 & 536,2 & 206,5 & 134,6 & 94,2 & 48,8 & 17,6 & 14,3 & 13,1 \\
B2 & 651,9 & 192,1 & 99,7 & 240,9 & 22,3 & 15,8 & 10,8 & 14,2 \\
B3 & 63,9 & 25,3 & 22,8 & 16,9 & 11,8 & 13,6 & 19,9 & 19,9 \\
B4 & 341,2 & 516,5 & 523,5 & 455,8 & 677,8 & 70,2 & 37,3 & 22,6 \\
B5 & 599,5 & 919,1 & 769,7 & 638,4 & 86,7 & 27,8 & 59,7 & 13,4 \\
B6 & 155,8 & 251,4 & 399,1 & 255,7 & $1.090,6$ & 229,9 & 138,6 & 78,3 \\
B7 & 697,4 & $1.016,3$ & 894,4 & 453,9 & 131,5 & 78,1 & 25,9 & 8,0 \\
B8 & 654,6 & 704,9 & $1.004,0$ & 725,3 & 161,7 & 96,2 & 36,6 & 27,8 \\
B9 & 686,7 & 622,2 & $1.040,0$ & 738,2 & 235,9 & 95,9 & 54,5 & 35,6 \\
B10 & 979,6 & 819,7 & 701,8 & 203,4 & 176,6 & 47,2 & 32,4 & 21,1 \\
\hline
\end{tabular}

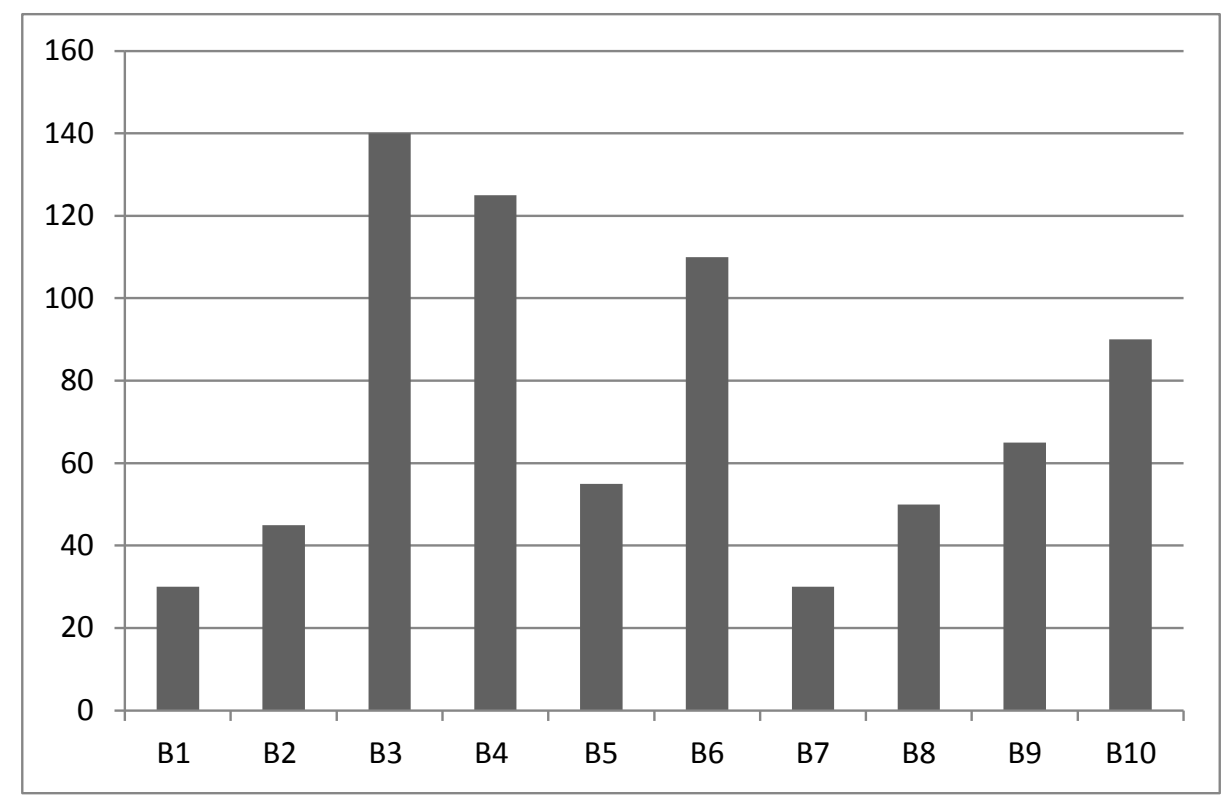

Figura 1 - Avaliação da qualidade do colostro das dez fêmeas nulíparas. 


\section{DISCUSSÃO}

Foram observadas diferenças estatísticas significativas entre momentos para as concentrações séricas de proteína total $(p=0,0002)$ e GGT $(<0.0001)$

Segundo Rea et al., (1996), Tyler et al., (1998) e Donovan et al., (1998), concentrações de PPT acima de 4,2g/dL são indicativos de boa transferência de imunidade passiva corroborando com os resultados obtidos neste trabalho, onde as medias para PPT mostraram-se acima do esperado nos 8 momentos, sendo: M1 6,96; M2 6,80; M3 6,86; M4 6,74; M5 6,48; M6 6,02; M7 6,10; M8 6,16g/dL, assim como mostra na tabela1. Individualmente os bezerros do experimento apresentaram valores acima de $4,2 \mathrm{~g} / \mathrm{dL}$ em todos os momentos, sendo $4,4 \mathrm{~g} / \mathrm{dL}$ a menor concentração apresentada pelo B3 no $\mathrm{M} 1$, (tabela 2) possivelmente por ingestão tardia do colostro e/ou interferência na absorção, já que o colostro da V3 (mãe do bezerro B3) apresentou valor de 140,00mg/MI (figura 1) enquadrando-se como de alta qualidade, segundo classificação de Coelho e Silper (2008).

No presente trabalho observou-se que nove dos dez bezerros apresentaram níveis elevados da atividade sérica de GGT até o M3(72 horas de vida), no qual o maior valor obtido da GGT foi de 1.090,6UI/L apresentado pelo B6 no M5 (tabela 3), atingindo 35 vezes os limites de normalidade dos animais adultos, corroborando com Perino et al., (1993) e Tessman et al., (1997), que em suas pesquisas descrevem o aumento dessa enzima até o terceiro dia de vida, entretanto os animais desse experimento não alcançaram 200 vezes os limites de normalidade citados por esses autores. A exceção foi feita com o bezerro numero 3 que apresentou valor de GGT de 22,8 UI/L no M3 (72 horas de vida) sendo que Perino et al., (1993) e Parish et al., (1997) consideram FTIP quando os animais apresentam concentrações de GGT inferior a 50,00UI/L durante os três dias de vida, e desta forma apenas um dos bezerros deste experimento apresentou FTIP através da avaliação da concentração de GGT, coincidindo também com o menor valor da PPT.

Perino et al., (1993) e Parish et al., (1997), ainda relatam que na primeira semana de vida a atividade sérica da GGT cai significativamente o que pode ser observado nos bezerros (B1, B3, B7, e B10) coincidindo com os autores citados. Já com os bezerros (B2, B5, B8 e B9) este fato ocorreu apenas no M5 (14 dias de vida). Os bezerros (B4 e B6) apresentaram queda da GGT apenas no M6 (28 dias de vida) divergindo um pouco dos autores citados (tabela 3).

Observamos que os valores séricos da GGT em 4 bezerros (B1, B2, B3 e B5) atingiram a normalidade no M6 (28 dias de vida), no M7 (35 dias de vida) só o B7 apresentou valores normais, já os bezerros B4, B8, e B10 obtiveram a normalidade no M8 (42 dias de vida), apenas os B6 e B9 não alcançaram os valores normais da GGT até o momento da última avaliação. 
Encontro de Ensino, Pesquisa e Extensão, Presidente Prudente, 21 a 24 de outubro, 2013

A avaliação geral dos animais utilizando média e desvio padrão revelou que os níveis de GGT são significativamente maiores nas primeiras 72 horas de vida e começam a cair a partir da primeira semana de vida (tabela 1). Esses dados condizem com a avaliação individual dos bezerros, onde houve aumento da GGT no M1, M2 e M3 e queda da mesma a partir do M4.

Das fêmeas nulíparas avaliadas neste experimento, seis (V3, V4, V5, V8, V9 e V10) enquadraram-se na categoria de colostro de alta qualidade (com mais de $50 \mathrm{mg} / \mathrm{mL}$, coluna verde) e quatro (V1, V2, V6 e V7) enquadraram-se na categoria intermediária (21 à 50mg/mL, coluna amarela) segundo Coelho e Silper (2008), demonstrando com isso que fêmeas nulíparas podem apresentar maior variação na qualidade do colostro (Figura 1). Cabe ressaltar ainda que a FTIP observada neste experimento não esta relacionada à qualidade do colostro.

\section{CONCLUSÃO}

Os resultados obtidos neste trabalho demonstraram que as fêmeas nulíparas avaliadas produziram colostro que variou de intermediário a alta qualidade, e portanto os bezerros obtiveram uma boa TIP, e que a FTIP verificada ocorreu por falha na ingestão, determinada por ingestão insuficiente ou não ingestão em tempo hábil de um colostro que era de alta qualidade.

\section{REFERÊNCIAS}

BOLZAN, G.N., ANTUNES, M.M., SCHWEGLER, E., PEREIRA, R.A., MARCIO NUNES CORRÊA, M.N.Importância da transferência da imunidade passiva para a sobrevivência de bezerros neonatos. 2010. NUPEEC - Núcleo de Pesquisa, Ensino e Extensão em Pecuária.

COELHO, S.G.; SILPER, B.F. Conheça as necessidades de fornecimento de colostro de acordo com a qualidade e com as diferentes raças. Colostro: quanto fornecer aos seus bezerros?, Minas Gerais, Dez., $2008 . \quad$ Disponível em <http://www.rehagro.com.br/siterehagro/publicação.do?cdnoticia=1811>. Acesso em: 15 Mai. 2010.

FEITOSA, F.L.F. Importância da Transferência da Imunidade passiva para sobrevivência de bezerros neonatos. Revista de Educação Contininuada - CRMV, v.2, n.3, p.17-22. 1999.

JAINUDEEN, M.R.; HAFEZ, E.S.E. Gestação, Fisiologia Pré-natal e Parto. In: HAFEZ, B.; HAFEZ, E.S.E. Reprodução Animal. 7.ed. Barueri, SP: Manole, 2004. cap.10.

KANEKO, J.J.; HARVEY, J.W.; BRUSS, M.L. Clinical biochemistry of domestic animals. 5.ed. San Diego: Academic Press, 1997.

LANDIM-ALVARENGA, F.C. Reconhecimento Materno do Concepto e Inicio da Placentação. In: PRESTES, N.C.; LANDIM-ALVARENGA, F.C. Obstetrícia Veterinária. Rio de Janeiro: Guanabara Koogan, 2006. cap.3: Doenças do Recém-nascido, p.102-128. 
MORIN, D.E.; McCOYT, G.C.; HURLEYT, W.L. Effects of Quality, and Timing of Colostrum Feeding and Addition of a Dried Colostrum Supplement on Immunoglobulin $\mathrm{G}_{1}$ Absorption in Holstein Bull Calves. Journal of Dairy Science, v.80, n.4, p.747-753, 1997. http://dx.doi.org/10.3168/ids.S00220302(97)75994-0

PARISH, S.M. Ruminant immunodeficiency discases. In: SMITH, B.P. (ed.). Large animal internal medicine. 2.ed. St. Louis: Mosby, 1996. p.1857-1860.

PARISH, S.M.; TYLER, J.W.; BESSER, T.E.; GAY, C.C.; KRYTENBERG, D. Prediction of serum IgG1 Concentration in Holstein Calves Using serum Gamma Glutamyltransferase Activity. Journal of Veterinary Internal Medicine, v.11, n.6, p.344-347. 1997. http://dx.doi.org/10.1111/j.19391676.1997.tb00478.x

PERINO, L.J.; SUTHERLAND, R.L.; WOOLLEN, N.E. Serum gamma-glutamyltransferase activity and protein concentration at birth and after suckling in calves with adequate and inadequate passive transfer of immunoglobulin G. Journal of the American Veterinary Medical Association, v.54, p.56-9. 1993.

RADOSTITS, O.M.; GAY,C.C.;BLOOD, D.C.; HINCHCLIFF, K.W. Clinica Veterinária: Um Tratado de Doenças dos Bovinos, Ovinos, Suínos, Caprinos e Eqüinos. 9.ed. Rio de Janeiro: Guanabara Koogan, 2000. cap.3: Doenças do Recém-nascido, p.102-128.

REA, D.E.; TYLER,J.W.; HANCOCK, D.D.; BESSER, T.E.; WILSON, L.; KRYTENBERG, D.S.; SANDERS, S.G. Prediction of calf mortality by use of tests for passive transfer of colostral immunoglobulin. Journal of the American Veterinary Medical Association, v.208, p.2047-9. 1996.

TESSMAN, R.K.; TYLER, J.W.; PARISH, S.M.; JOHNSON, D.L.; GANT, R.G.; GRASSESCHI, H.A. Use of age serum gamma-glutamyltransferase activity to assess passive transfer status in lambs. Journal of the American Veterinary Medical Association, v.211, p.1163-4. 1997.

TIZARD, I.R. Imunologia Veterinária: Uma Introdução. 6.ed. São Paulo: ROCA, 2002. cap.19: Imunidade no Feto e no Recém-nascido, p.231-246.

TYLER, J.W.; HANCOCK, D.D.; PARISH, S.M.; REA, D.E.; BESSER, T.E.; SANDERS, S.G.; WILSON, L.K. Evaluation of 3 Assays for Failure of Passive Transfer in Calves. Journal of Veterinary Internal Medicine, v.10, n.5, p.304-307. 1996. http://dx.doi.org/10.1111/j.1939-1676.1996.tb02067.x

TYLER, J.W.; HANCOCK, D.D.; WIKSIE, S.E.; HOLLER, S.L.; GAY, J.M.; GAY, C.C. Use of serum Protein Concentration to Predict Mortality in Mixed-Source Dairy Replacement Heifers. Journal of Veterinary Internal Medicine, v.12, n.2, p.79-83. 1998. http://dx.doi.org/10.1111/j.19391676.1998.tb02099.x 